\title{
SO SÁNH ĐĂC ĐIẺM LÂM SÀNG, HìNH ẢNH ĐIỆN QUANG Ở BỆNH NHÂN CHẤN THƯO'NG CỘT SỐNG VÙNG NGỰC THÁT LƯNG DENIS IIB THEO PHÂN LOẠI CHIA SẺ LỰC TẢI CỦA ĐỐT SỐNG TỔN THƯƠNG
}

\author{
Nguyễn Ngọc Quyền ${ }^{凶}$, Lê Hùng Trường, Vũ Hồng Vân \\ Bệnh viện Trung ương Quân đội 108
}

So sánh đặc điểm lâm sàng, hình ảnh điện quang theo phân loại chia sẻ lực tải của thân đốt sống ở bệnh nhân chấn thương cột sống vùng ngực thắt lưng mất vững loại Denis IIB. Nghiên cứu cắt ngang mô tả, được tiến hành trên 40 bệnh nhân bị chấn thương vỡ nhiều mảnh thân đốt sống ở một đốt sống vùng bản lề ngực - thắt lưng có chỉ định phẫu thuật. Không có sự khác biệt cóýnghĩa thống kê về tuổi, giới, mức độ đau cột sống và tổn thương thần kinh giữa hai nhóm điểm LSC. Trung bình góc gù thân đốt sống, góc gù vùng cột sống, khoảng liên cuống cung của đốt sống tổn thương ở nhóm điểm LSC 77 cao hơn nhóm điểm LSC < 7 nhưng sự khác biệt không có ýnghĩa thống kê. Nhóm có điểm $L S C \geq 7$ có mức độ hẹp ống sống nặng hơn nhóm có điểm $L S C<7$ với sự khác biệt có ýnghĩa thống kê.

Từ khóa: Vỡ nhiều mảnh cột sống, dấu hiệu lâm sàng, hình ảnh điện quang, phân loại theo lực tải.

\section{I. ĐẠT VẤN ĐỀ}

Chấn thương cột sống bản lề ngực - thắt lưng là tổn thương thường gặp nhất trong chấn thương cột sống. Tại Việt Nam, vỡ nhiều mảnh thân đốt sống chiếm tỉ lệ cao nhất từ $70 \%$ đến trên $80 \%$ trong tổng số chấn thương vùng bản lề ngực - thắt lưng. ${ }^{1}$ Chấn thương này được Denis $F$ chia thành năm loại trong đó chấn thương có tổn thương thân đốt sống kèm tâm sụn đĩa đệm phía trên của đốt sống tổn thương (Denis IIB) chiếm tỉ lệ cao nhất. ${ }^{2} \mathrm{MC}$ Cormack đưa ra phân loại chia sẻ lực tải của đốt sống tổn thương (Load Sharing Classiffication: LSC) dựa trên mức độ nặng của tổn thương thân đốt sống với mục đích tiên lượng sự thất bại của dụng cụ cố định cột sống cấu hình ngắn phía sau, các trường hợp có điểm LSC $\geq 7$ thì nguy cơ thất bại dụng cụ cao. ${ }^{3}$ Cho tới nay có một số nghiên cứu tìm hiểu sự liên quan giữa một

Tác giả liên hệ: Nguyễn Ngọc Quyền ,

Bệnh viện Trung ương Quân đội 108

Email: bsquyenptcs108@gmail.com

Ngày nhận: 01/09/2021

Ngày được chấp nhận: 22/09/2021 số đặc điểm lâm sàng, hình ảnh giữa liên quan và điểm LSC. ${ }^{4-7}$ Việc tìm hiểu sự khác nhau về tình trạng lâm sàng, đặc điểm hình ảnh giữa hai nhóm điểm LSC là có ý nghĩa trong việc góp phần đánh giá ưu nhược điểm của hệ thống phân loại này. Tuy nhiên, chưa có nghiên cứu nào so sánh về đặc điểm lâm sàng, tổn thương hình ảnh giữa hai nhóm điểm LSC của bệnh nhân vỡ nhiều mảnh thân đốt sống mất vững vùng bản lề ngực - thắt lưng.

\section{II. ĐỐl TƯƠ'NG VÀ PHƯO'NG PHÁP}

\section{1. Đối tượng}

Các bệnh nhân được chẩn đoán là chấn thương cột sống vùng bản lề ngực - thắt lưng (từ T11 đến L2), phân loại theo Denis thuộc nhóm IIB, có mất vững cột sống được chỉ định phẫu thuật. Loại trừ bệnh nhân có hình ảnh Xquang quy ước và cắt lớp vi tính (CLVT) không đủ chất lượng để đánh giá, bệnh nhân có các bệnh lý kèm theo ảnh hưởng đến việc đánh giá triệu chứng lâm sàng như di chứng tai biến mạch máu não, loạn thần..., bệnh nhân có chấn thương nặng kèm theo như chấn thương 
sọ não, chân thương ngực, bụng...

Nghiên cứu mô tả được tiến hành trên 40 bệnh nhân kế tiếp nhau có tuổi trung bình 46,7 tuổi (từ 21 đến 68 tuổi) bị chấn thương vỡ nhiều mảnh thân đốt sống gây mất vững cột sống vùng ngực thắt lưng có chỉ định phẫu thuật tại Bệnh viện Trung ương Quân đội 108 từ tháng 1 năm 2013 đến tháng 1 năm 2017.

\section{Phương pháp nghiên cứu}

Thiết kế nghiên cứu: Nghiên cứu mô tả, cắt ngang.

Cỡ mẫu: Chọn mẫu thuận tiện, bệnh nhân đáp ứng đủ tiêu chuẩn lựa chọn và loại trừ trong thời gian nghiên cứu đều được lấy vào nghiên cứu.

Địa điểm nghiên cứu: tại khoa Phẫu thuật cột sống - Bệnh viện Trung ương Quân đội 108.

Thời gian: từ tháng 1 năm 2013 đến tháng

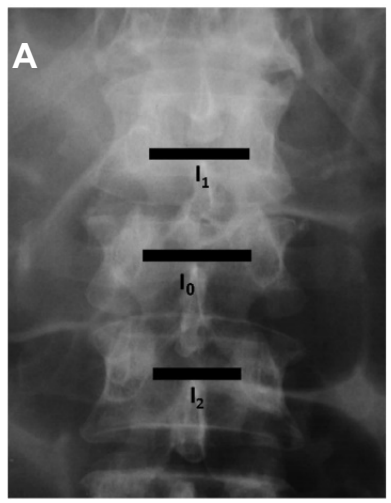

B

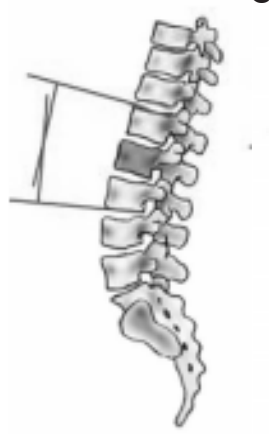

1 năm 2017.

Các biến và chỉ số nghiên cứu:

Tình trạng đau cột sống theo thang điểm VAS, tổn thương thần kinh theo phân độ của ASIA (American Spinal Injury Association). Thu thập hình ảnh Xquang thường quy (thẳng nghiêng) được chụp ở tư thế nằm. Hình ảnh CLVT trước phẫu thuật của bệnh nhân: bệnh nhân được chụp phim CLVT ở tư thế nằm với các lát cắt ngang có độ dày $3,75 \mathrm{~mm}$, sau đó sử dụng phần mềm tái tạo hình ảnh dựng các lát cắt dọc có độ dày $1,25 \mathrm{~mm}$ và có dựng hình $3 \mathrm{D}$.

+ Trên phim Xquang thẳng: Sự giãn rộng của khoảng cách cuống cung được tính ra tỉ lệ \% theo công thức được đưa ra bởi Willen và cộng sự. ${ }^{4}$ Tỉ lệ \% khoảng liên cuống cung $=\left[\left(I_{1}+I_{2}\right) / 2-I_{0}\right] /\left[\left(I_{1}+I_{2}\right) / 2\right]^{*} 100$. Với $I_{1}$ : khoảng liên cuống đốt sống trên, $\mathrm{I}_{0}$ : khoảng liên cuống đốt sống tổn thương, $\mathrm{I}_{2}$ : khoảng liên cuống đốt sống dưới (Hình 1).

C
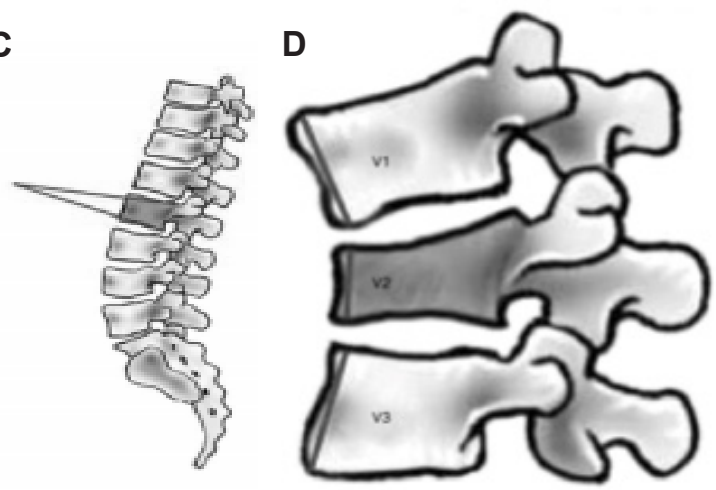

Hình 1. Cách đo khoảng cách liên cuống cung, góc gù vùng, góc gù đốt sống và mức độ lún bò̀ trước đốt sống

+ Xquang nghiêng: Đo các chỉ số sau: Góc gù thân đốt sống, góc gù vùng, mức độ lún của bờ trước thân đốt sống (Hình 1).

Góc gù vùng: là góc giữa hai đường thẳng đi qua mặt trên thân đốt trên và mặt dưới thân đốt dưới liền kề đốt sống tổn thương. Góc gù thân đốt sống: là góc tạo bởi giữa đường thẳng đi qua mặt trên và mặt dưới của đốt sống tổn thương. Mức độ lún của bờ trước thân đốt sống tổn thương: lần lượt xác định chiều cao cột trước thân đốt sống chấn thương (Ký hiệu V2) và hai thân đốt sống liền kề ( Ký hiệu V1, V3). Khi đó mức độ lún chiều cao bờ trước thân đốt sống tổn thương được tính theo công thức: \% lún bờ trước thân đốt sống $=[(\mathrm{V} 1+\mathrm{V} 3) / 2-\mathrm{V} 2] /[(\mathrm{V} 1+$ v3)/2]¹00.

Trên lát cắt ngang phim CLVT xác định mức độ hẹp ống sống (HOS) của đốt sống tổn thương theo công thức: Tỉ lệ \% HOS $=[(A+C) / 2$ $-B] /[(A+C) / 2] \times 100$. Trong đó $A$ là khoảng cách 
trước sau của ống sống ở đốt sống kế trên, C là khoảng cách của trước sau của ống sống ở đốt sống dưới, $B$ là khoảng cách trước sau của ống sống tại đốt sống tổn thương. Hình ảnh được sử dụng để đo là lát cắt ngang qua giữa cuống cung của đốt sống.

Dựa vào hình ảnh Xquang và CLVT phân loại tổn thương đốt sống theo LSC của Mc Cormack. ${ }^{3}$

Bảng 1. Cách tính điểm mức độ tổn thương theo phân loại LSC

\begin{tabular}{lllcc}
\hline Độ & $\begin{array}{c}\text { Vỡ vụn trên phim } \\
\text { CLVT }\end{array}$ & $\begin{array}{c}\text { Sụ̣ di lệch của mảnh vỡ lát } \\
\text { cắt ngang phim CLVT }\end{array}$ & $\begin{array}{c}\text { Sự thay đổi góc gù } \\
\text { thân đốt sống }\end{array}$ & Điểm \\
\hline I & $<30 \%$ & Nằm sát nhau $(<2 \mathrm{~mm})$ & $\leq 30$ & 1 \\
\hline II & $30-60 \%$ & $\begin{array}{l}\geq 2 \mathrm{~mm} \text { và }<50 \% \text { đường vỡ } \\
\text { thân đốt }\end{array}$ & $40-90$ & 2 \\
\hline III & $>60 \%$ & $\begin{array}{l}\geq 2 \mathrm{~mm} \text { và } \geq 50 \% \text { đường vớ } \\
\text { thân đốt }\end{array}$ & $\geq 100$ & 3 \\
\hline
\end{tabular}

So sánh sự khác nhau giữa về đặc điểm chung, dấu hiệu lâm sàng và tổn thương trên hình ảnh điện quang giữa nhóm bệnh nhân có điểm LSC $<7$ với nhóm có điểm LSC $\geq 7$.

\section{Xử lý số liệu}

Số liệu được xử lý bằng phần mềm thông kê y học SPSS 16.0 với giá trị $p<0,05$ là sự khác biệt có ý nghĩa thống kê.

\section{4. Đạo đức nghiên cứu}

Nghiên cứu được thông qua hội đồng đạo đức $Y$ học - Viện nghiên cứu khoa học $Y$ Dược lâm sàng 108. Bệnh nhân và người nhà được giải thích đầy đủ về quy trình nghiên cứu và đồng ý tham gia nghiên cứu. Các thông tin về hồ sơ, bệnh án của bệnh nhân đều được chúng tôi bảo mật, chỉ sử dụng với mục đích khoa học và không dùng cho bất kỳ mục đích nào khác.

\section{KÉT QUẢ}

\section{1.Đặc điểm lâm sàng}

Độ tuổi trung bình của 40 bệnh nhân nghiên cứu là 46,6 4 11,7 (21 - 68 tuổi) với 55\% nam và $45 \%$ nữ. Nguyên nhân gây chấn thương vỡ nhiều mảnh thân đốt sống vùng bản lề ngực - thắt lưng do ngã cao 31 bệnh nhân chiếm $77,5 \%$; 5 bệnh nhân tai nạn giao thông chiếm 12,5\%; nguyên nhân khác như ngã cầu thang, tủ đè... chiếm 10\% (4bệnh nhân). Vị trí đốt sống tổn thương thường gặp nhất là L1 với 24 bệnh nhân chiếm $60 \%$; 11 bệnh nhân ở L2 chiếm tỉ lệ 27,5\%; 05 bệnh nhân (12,5\%) tổn thương đốt sống $T 12$ và không có trường hợp nào tổn thương ở T11 trong nghiên cứu này. Không có sự khác biệt có ý nghĩa thống kê về điểm LSC trung bình giữa nhóm bệnh nhân nam và nữ, nhóm có tổn thương và không tổn thương thần kinh (bảng 1).

Bảng 2. Điểm LSC trung bình theo giới, nhóm có tổn thương thần kinh và không tổn thương thần kinh $(n=40)$

\begin{tabular}{llcc}
\hline & LSC trung bình \pm SD & $\begin{array}{c}\text { p } \\
\text { (Mann - Whitney U test) }\end{array}$ \\
\cline { 1 - 2 } Giới & Nam (22) & $6,8 \pm 1,0$ & 0,964 \\
\cline { 2 - 3 } & Nữ (18) & $6,8 \pm 1,2$ & \\
\hline
\end{tabular}


LSC trung bình \pm SD

p

(Mann - Whitney U test)

\begin{tabular}{llll}
\hline \multirow{2}{*}{$\begin{array}{l}\text { Tổn thương thần } \\
\text { kinh }\end{array}$} & Có (11) & $7,2 \pm 1,1$ & 0,183 \\
\cline { 2 - 3 } & Không (29) & $6,7 \pm 1,0$ &
\end{tabular}

Không có sự khác nhau có ý nghĩa thống kê về trung bình tuổi, mức độ đau cột sống giữa hai nhóm bệnh nhân có điểm LSC $<7$ và LSC $\geq 7$ (bảng 3).

\section{Bảng 3. Trung bình tuổi, điểm VAS theo nhóm điểm LSC}

\begin{tabular}{|c|c|c|c|}
\hline \multirow{2}{*}{ Chỉ số } & \multicolumn{2}{|c|}{ Điểm LSC } & \multirow{2}{*}{$\begin{array}{c}p \\
\text { (Mann - Whitney U test) }\end{array}$} \\
\hline & $<7(17)$ & $\geq 7(23)$ & \\
\hline Tuổi trung bình \pm SD & $49,0 \pm 8,2$ & $44,8 \pm 13,6$ & 0,270 \\
\hline VAS trung bình $\pm S D$ & $7,7 \pm 0,8$ & $7,9 \pm 0,7$ & 0,370 \\
\hline
\end{tabular}

\section{3. Đặc điểm tổn thương cột sống trên chẩn đoán hình ảnh}

Bảng 4. Tổn thương trên hình ảnh điện quang theo nhóm điểm LSC ( $n=40)$

\begin{tabular}{|c|c|c|c|}
\hline \multirow{2}{*}{ Chỉ số } & \multicolumn{2}{|c|}{ Điểm LSC } & \multirow{2}{*}{$\begin{array}{c}p \\
\text { (Mann - Whitney U test) }\end{array}$} \\
\hline & $<7(17)$ & $\geq 7(23)$ & \\
\hline Lún bờ trước thân đốt sống (\%) & $47,3 \pm 12,3$ & $51,5 \pm 9,5$ & 0,212 \\
\hline Góc gù vùng (độ) & $18,9 \pm 8,0$ & $19,3 \pm 8,3$ & 0,890 \\
\hline Góc gù thân đốt sống (độ) & $22,7 \pm 5,3$ & $25,8 \pm 5,8$ & 0,090 \\
\hline Khoảng liên cuống cung (\%) & $10,8 \pm 7,9$ & $13,8 \pm 8,8$ & 0,273 \\
\hline HOS (\%) & $45,1 \pm 13,8$ & $53,8 \pm 11,9$ & 0,040 \\
\hline
\end{tabular}

Bảng 4 cho thấy trung bình mức độ lún bờ trước thân đốt sống, góc gù vùng, góc gù thân đốt sống, khoảng cuống cung giãn rộng ở nhóm điểm LSC $\geq 7$ lớn hơn ở nhóm LSC $<7$, nhưng sự khác biệt không có ý nghĩa thống kê. Mức độ HOS trung bình ở nhóm có điểm LSC < 7 thấp hơn nhóm có điểm LSC $\geq 7$ với sự khác biệt có ý nghĩa thống kê.

\section{BÀN LUẠN}

Năm 1994, McCormack và cộng sự đã đưa ra hệ thống phân loại theo chia sẻ lực tải của đốt sống tổn thương dựa trên ba đặc tính của tổn thương: mức độ vỡ vụn của thân đốt sống, sự di lệch của các mảnh xương vỡ, mức độ nắn chỉnh của góc gù cột sống. Mỗi đặc tính chia ra thành ba mức độ từ 1 đến 3 tương ứng với mỗi mức độ là số điểm. Nếu tổng điểm từ 7 trở lên thì nguy cơ thất bại nếu phẫu thuật cố định lối sau. ${ }^{3}$ Câu hỏi đặt ra là đặc điểm lâm sàng, tổn thương trên hình ảnh điện quang của bệnh nhân có tương ứng với điểm LSC hay không?

Nghiên cứu này cho thấy không có sự khác biệt có ý nghĩa thống kê về trung bình điểm VAS đau cột sống giữa nhóm điểm $<7$ và $\geq 7$. Điều này cho thấy mức độ nặng của tổn thương đốt sống không tương đồng với mức độ đau cột sống. Điều này được lý giải là đau cột sống sau chấn thương do nhiều yếu tố gây ra, trong khi đó phân loại LSC chỉ tập trung vào hình thái tổn thương đốt sống tổn thương trên hình ảnh. Về liên quan giữa mức độ tổn thương thần kinh 
và điểm LSC, kết quả cho thấy không có sự khác biệt có ý nghĩa thống kê về điểm LSC giữa hai nhóm có và không có tổn thương thần kinh. Điều này được lý giải bởi phân loại LSC dựa chủ yếu vào tổn thương trên hình ảnh, không bao gồm yếu tố tổn thương thần kinh. Bên cạnh đó, ngay cả vấn đề liên quan giữa tổn thương thần kinh và mức độ HOS cũng còn tranh luận trong $Y$ văn. Meves và cộng sự nghiên cứu trên 184 trường hợp vỡ nhiều mảnh thân đốt sống thấy rằng có mối tương quan dương tính giữa tổn thương thần kinh và mức độ HOS nhưng sự tương quan này yếu với rho $=0,35 .{ }^{5}$ Nhưng Vascaro và cộng sự nghiên cứu 43 trường hợp vỡ nhiều mảnh thân đốt sống vùng bản lề ngực - thắt lưng không thấy có sự liên quan giữa mức độ HOS và tổn thương thần kinh ${ }^{6}$ Bên cạnh đó Radcliff và cộng sự cũng không thấy có sự liên quan giữa điểm LSC và mức độ tổn thương thần kinh. ${ }^{7}$

Radcliff và cộng sự cũng tìm hiểu giá trị điểm LSC trong chẩn đoán tổn thương hệ thống dây chằng phía sau nhưng không tìm thấy sự liên quan giữa chúng. ${ }^{7}$ Trong nghiên cứu này chúng tôi tìm hiểu sự liên quan giữa tổn thương trên hình ảnh điện quang và điểm LSC, kết quả nghiên cứu cho thấy giá trị trung bình lún bờ trước đốt sống, góc gù vùng, góc gù thân đốt sống có điểm LSC $\geq 7$ cao hơn nhóm LSC $<7$, nhưng sự khác biệt không có ý nghĩa thống kê với $p>0,05$. Mức độ HOS ở nhóm LSC 7 cao hơn rõ rệt so với nhóm có điểm LSC < 7 với sự khác biệt có ý nghĩa thống kê $p<0,05$. Điều này được lý giải do điểm LSC là tổng hợp điểm của ba yếu tố: điểm vỡ vụn thân đốt sống, mức độ di lệch mảnh vỡ và sự thay đổi góc gù thân đốt sống sau nắn chỉnh. Các yếu tố này không liên quan đến mức độ giảm chiều cao bờ trước thân đốt sống, góc gù vùng hay góc gù thân đốt sống. Tổn thương đốt sống vỡ vụn hoàn toàn trên phim cắt lớp vi tính nhưng góc gù vùng, góc gù cột sống lại có thể không cao khi đo trên phim điện quang. Về mức độ HOS thì có liên quan đến mức độ nặng của tổn thương đốt sống theo LSC là vì phân loại LSC có dựa vào sự di lệch của mảnh vỡ ra ngoại vi của trung tâm thân đốt sống để tính điểm trong đó có sự di lệch về phía sống sống làm ống sống hẹp lại. Điểm LSC căng cao khi sự di lệch của các mảnh vỡ vụn càng lớn do đó mức độ HOS có thể cũng tăng theo (hình 2).

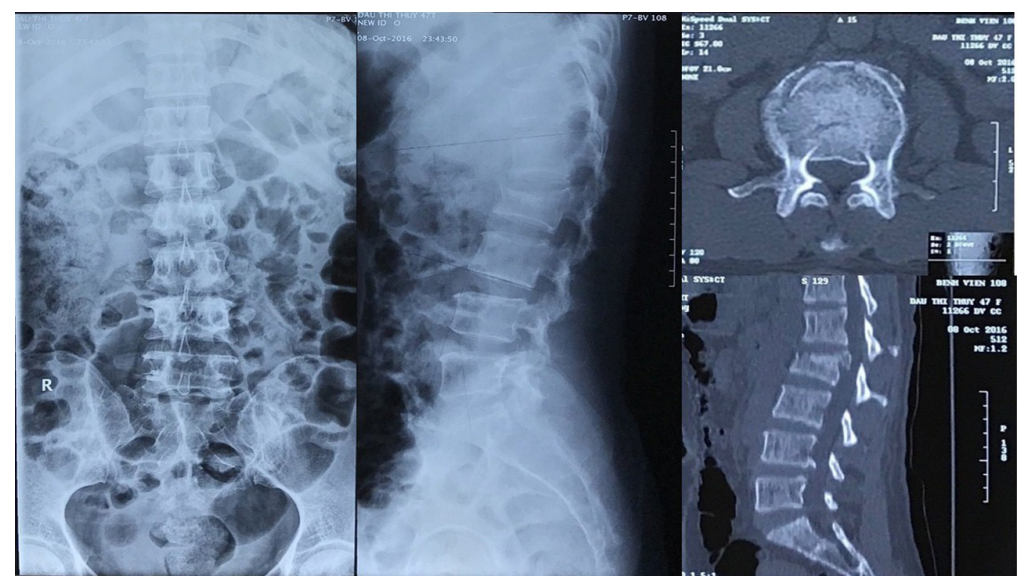

Hình 2. Hình ảnh bệnh nhân minh họa: Xquang thẳng: Khoảng cuống cung L2 giãn rộng là 1,7\%. Xquang nghiêng: Lún L2, tỉ lệ lún bờ trước 31,9\%, góc gù vùng từ L1 đến L3: $26^{\circ}$, góc gù thân đốt sống $L 2$ là 250; Cắt lớp vi tính: lát cắt ngang thấy có mảnh xương di lệch làm HOS, tỉ lệ HOS 43,3\%. Điểm LSC: 7 điểm 
Nhược điểm của nghiên cứu này là số lượng bệnh nhân nghiên cứu còn ít, chỉ tập trung ở các bệnh nhân được phân loại Denis IIB và có chỉ định phẫu thuật. Vì vậy, một nghiên cứu có số lượng bệnh nhân lớn hơn, đa dạng hơn sẽ có mang lại ý nghĩa hơn. Tuy nhiên, xét về loại tổn thương cột sống thường gặp ở vùng bản lề ngực thắt lưng là loại Denis IIB và phân loại LSC chủ yếu để cho các bệnh nhân có chỉ định phẫu thuật thì nghiên cứu này có thể góp phần vào làm rõ ưu nhược điểm của phân loại LSC.

\section{KÉT LUẦN}

Không có sự liên quan về mức độ đau cột sống, tổn thương thần kinh với điểm LSC. Nhóm có điểm LSC $\geq 7$ có trung bình lún bờ trước thân đốt sống, góc gù vùng, góc gù thân đốt sống, sự giãn rộng liên cuống cung và mức độ HOS cao hơn nhóm có điểm LSC < 7, tuy nhiên sự khác biệt không có ý nghĩa thống kê ngoại trừ sự khác biệt về mức độ HOS. Phân loại LSC không bao hàm được mức độ nặng của tổn thương của chấn thương cột sống cả về lâm sàng cũng như các dấu hiệu trên hình ảnh điện quang.

\section{TÀI LIẸU THAM KHẢO}

1. Nguyễn Trọng Tín. Điều trị phẫu thuật gãy lún nhiều mảnh cột sống lưng - thắt lưng bằng phương pháp giải ép tối thiểu. Luận án Tiến sĩ Y học. 2010, Đại học Y Dược Thành phố Hồ Chí Minh.
2. Denis, F. The Three Column Spine and its Significance in the classification of acute thoracolumbar. Spine. 1983;8(8):817 - 831. doi: 10. 1097/00007632 - 198311000 - 00003.

3. McCormack T, Karaikovic EE, and Gaines RW. The load sharing classification of spine fractures. Spine (Phila Pa 1976). 1994;19(15):1741 - 4. doi: 10. 1097/00007632 199408000 - 00014.

4. Caffaro MF and Avanzi O. Can the interpedicular distance reliably assess the severity of thoracolumbar burst fractures? Spine (Phila Pa 1976). 2012;37(4):E231 - 6. doi: 10. 1097/BRS. 0b013e318237b0cf.

5. Meves R and Avanzi O. Correlation among canal compromise, neurologic deficit, and injury severity in thoracolumbar burst fractures. Spine (Phila Pa 1976). 1994;31(18):2137 - 41. doi: 10. 1097/01. brs. 0000231730. 34754. 9e.

6. Vaccaro AR, Nachwalter RS, Klein GR, et al. The significance of thoracolumbar spinal canal size in spinal cord injury patients. Spine (Phila Pa 1976). 2001;26(4):371 - 376. doi: 10. 1097/00007632 - 200102150 - 00013.

7. Radcliff K, Kepler CK, Rubin TA, et al. Does the load - sharing classification predict ligamentous injury, neurological injury, and the need for surgery in patients with thoracolumbar burst fractures? J Neurosurg Spine. 2012;16(6):534 - 538. doi: 10. 1097/00007632 $200102150-00013$.

\section{Summary}

\section{COMPARISON OF CLINICAL FEATURES AND RADIOLOGICAL FINDING IN PATIENTS WITH THORACOLUMBAR BURST FRACTURE DENIS TYPE IIB ACCORDING TO LOAD SHARING CLASSIFICATION}

This study was performed to compare the clinical radiological features according to load sharing classification of patients with unstable thoracolumbar burst fracture, Denis type IIB. A cross-sectional, descriptive study was performed in 40 patients with isolated unstable thoracolumbar burst fractures. There was no significant difference between both LSC groups about age, gender, spinal pain intensity 
and severity of spinal cord injury. The mean of anterior vertebral body height loss, regional kyphotic angle, vertebral kyphotic angle and the windening of interpediclar distance at injured level in the group of LSC $\geq 7$ were higher than group of LSC $<7$ but the difference was not significant. The average of canal compromise in the group ofLSC $\geq 7$ was more severe than the group of LSC $<7$ with significant difference.

Keywords: Burst fracture, clinical features, radiological findings, load sharing classification 